The Geneva Papers on Risk and Insurance, 22 (No. 83, April 1997) 194-210

\title{
Market-Based Environmental Audits and Environmental Risks: Implementing ISO 14000*
}

\author{
by Paul R. Kleindorfer**
}

\section{Introduction}

This paper examines the costs and benefits of new market-based approaches to the regulation of environmental risks. Specifically, we will be concerned with approaches which emphasize standards and inspections or audits, with such audits being provided by qualified third parties. As in the accounting profession, these profit-oriented third parties may provide other services, e.g. consulting and systems development, in addition to their auditing services. This approach is in line with the move toward market-based implementation of environmental regulation, whereby information is provided to regulators and to affected parties in an on-going fashion, and the very provision of this information thereby provides the leverage through which stakeholders inform themselves and exert pressure on companies to improve their environmental performance. ${ }^{1}$

This paper considers these developments in light of a particular international initiative, the ISO 14000 standards, which are beginning to gain momentum as a vehicle for improving environmental management. ${ }^{2}$ ISO 14000 is actually a series of management system standards, covering such areas as process documentation, training, life-cycle assessment procedures and management reporting, and accountability for environmental performance. For each such standard, companies wishing to obtain certification must establish internally consistent and defined processes for each of the areas covered by the respective standard.

* Presented at the Geneva Association Meeting, Geneva, August 28-30,1996.

** Universal Furniture Professor of Decision Sciences and Economics and Professor of Public Policy and Management. The Wharton School. University of Pennsylvania. The author thanks Tom Eggert, Elizabeth Kluesner, Howard Kunreuther, Eric Orts, Irv Rosenthal and Jeff Smoller for comments and helpful discussions on this research. Errors and opinions belong to the author.

1 For a detailed discussion of the law and economics foundations of this so-called "informational regulation", see Kleindorfer and Orts (1996), which serves as the foundation for several of the arguments presented here.

2 A related area of development in the European Union has been EMAS (Eco-Management and Audit Scheme) which has a similar structure to the ISO 14000 standards. Indeed, many observers have argued that these two management standards and audit schemes should have a confluence with one another (e.g., Platzer et al., 1995). I discuss below the points of similarity and difference between EMAS and ISO 14000 , but I focus primarily on ISO 14000 in what follows. 
Certification under these standards is voluntary and may be pursued either for a particular facility or for an entire company. Certification, which is renewed on an annual basis, requires the company to verify via third-party or internal audit that the company is following its own established procedures. As many observers have noted, certification does not by itself verify that these procedures are best practice or even reasonable. It only verifies that the company is doing what it claims.

An ISO 14000 audit provides two key pieces of information to stakeholders: the structure of the environmental management system (EMS) implemented in a company, and the fact that either the company or a qualified third party has audited this company's operations and found that the company's operations comport with the structure of its asserted management system. By incorporating into the objectives of the EMS and associated audit specific regulatory compliance objectives, including documentation and communication requirements, the audit provides a certification and record of exceptions of the company's compliance with the specified regulatory requirements. Since third parties engaged in this activity will have incentives to provide customer-focused support, it is reasonable to expect that competition in quality and value-adding services among third-party auditors will naturally develop. Such service innovation could add significant economic benefits for business, while helping to assure improvement in environmental performance and compliance with applicable regulations. While this approach cannot and should not remove the responsibility for environmental compliance and enforcement activities from public agencies charged with such activities, it can provide increased resources to accomplish these activities efficiently through the market. The possibility of realizing these potential net benefits is what has drawn international attention to such standards as ISO 14000 . However, it remains to be seen whether these net benefits will materialize, and this paper will point to some areas of uncertainty and caution in this regard.

The paper proceeds as follows. In the next section, we consider alternative forms of environmental regulation and provide a basic framework for understanding how information and auditing standards such as ISO 14000 fit with other forms of environmental regulation. In section 3 we briefly describe the structure of ISO 14000 and possible approaches to its implementation. In section 4, we analyze the potential benefits from international standards such as ISO 14000, including improved environmental performance and lower compliance costs for business, improved risk management and insurance partnerships, reduced regulatory transactions costs, and improved local (community) relations. In section 5 we describe a number of barriers to achieving these benefits, including the problem of monitoring and licensing of third parties, lack of credibility of the certification process itself, and the problems of crafting the public/private partnership necessary to maintain regulatory enforcement responsibility in the public sector while enabling market-based value-adding approaches to auditing and systems improvement in the private sector. Section 6 is a concluding commentary.

\section{Background on environmental regulation}

This section provides a brief introduction to environmental regulation which will be useful in understanding the role of environmental auditing. We begin with Figure 1 which depicts the relationship between problem context, standards, and regulation. Regulation begins in response to a particular problem and its context. The context of the problem may itself be a primary determinant of the form which regulations and standards take. If the 
problem arises, for example, as a part of a well-publicized disaster, then speedy and perhaps heavy-handed regulation, with monitoring by the regulator, can be expected. If the problem arises out of an industry working group, then standards may tend to be more performancebased and regulation more light-handed. In response to the problem of context, we envision three stages of regulation:

Figure I: Regulatory framework

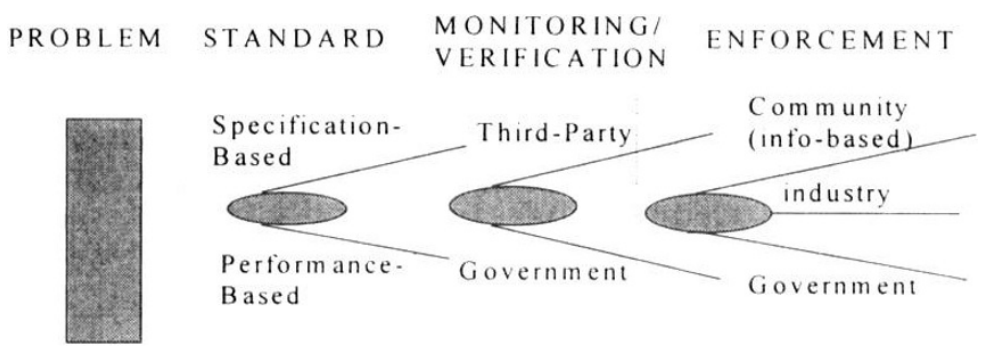

Stage one: A performance or specification standard is defined more or less precisely. The standard may be defined by the regulator, the firm, an association of professionals interested in the subject of the standard, or a public interest group or group of scientists concerned with the problem.

Stage two: A method or mechanism for monitoring and verifying actual performance is set up in order to know whether the standard is being achieved. This oversight can take various regulatory forms depending, in part, on the technical and scientific capabilities of measurement. The government can directly monitor and verify compliance with standards by inspections. Increasing penalties for non-compliance would increase pressure for internal monitoring/verification and decrease the need for inspections. Alternatively, the regulated entities themselves may set up monitoring and verification procedures, namely, internal environmental management and auditing systems. Or an entity may hire outside auditors to monitor and verify.

Stage three: Punishments and rewards are established to encourage compliance (or performance "beyond compliance") with adopted standards. Punishment may include civil fines, punitive damages, and criminal penalties. Informational disclosure of violations of standards may also punish a regulated entity in the market or in the form of adverse public opinion. Rewards may include not only the absence of governmental penalties, but some form of government benefit or subsidy, e.g. in the form of reduced regulatory scrutiny. There may also be rewards resulting from positive information delivered to the market and the public. For example, firms with reputations for environmental responsibility may see increased sales in segments of the market which are environmentally sensitive.

From this framework, we can identify several classes of regulation. We refer to any regulation emanating from a specification standard as specification-based. Any regulation emanating from a performance standard is performance-based. Thus, the top half of the tree in Figure 1 is specification-based and the bottom half is performance-based. What we refer to as informational regulation (IR) can be used in either the monitoring/verification 
stage or in the enforcement stage. In either stage, IR is any regulation which provides information to stakeholders on company operations. IR can, therefore, complement either performance-based or specification-based regulation. For example, requiring the publication of certain information may provide a verified signal of regulatory compliance. Alternatively, IR can require that specified third parties or the public have access to certain information about the company's operations, without mandating a particular regulatory result or outcome.

IR comes in different forms to address different problems. For example, in the U.S., the Toxic Release Inventory and Risk Management Plans and Accident History Report under 112(r) of the Clean Act Air Amendments require government-mandated informational reporting. In the European Union, eco-labels involve governmental standards - although independent private standards may also be employed ${ }^{3}-$ but they are not usually mandatory in the sense that all consumer products of a certain sort must carry an eco-label. Thus, IR also involves standards, even though their "enforcement" may be indirect. Sometimes it is not the government that "enforces" the standards in an IR system, but rather economic markets, citizen groups, or public opinion that supply "regulatory" pressure through market dynamics or moral persuasion. In addition, IR may involve the creation and development of non-governmental standards as to what constitutes reasonable systems, procedures or outcomes. These standards may originate from within the regulated business itself, as is the case, for example, with ISO 14000 where private industry has provided the main input on the appropriate structure of the various ISO 14000 standards. The Responsible Care program of the Chemical Manufacturers Association is another salient example of an industry generated standard (see Baram, 1994). Another example is the set of principles of the non-profit Coalition for Environmentally Responsible Economies (CERES) ${ }^{4}$ For such industry-generated standards to work effectively from a regulatory perspective, a credible monitoring and disclosure system must be developed with its own set of procedural standards.

Related to the discussion of IR in environmental regulation is the increasing reliance, at least in political rhetoric, on market-based approaches to regulation. Market-based regulation has come to mean any regulation that fosters the use of markets in place of regulatory bureaucracies to accomplish a given regulatory objective. In the context of Figure 1, market-based approaches could enter all three phases. At the standards phase, relying on process innovation through market forces may allow the adoption of performance standards rather than specification standards. At the monitoring stage, third parties may be used to verify compliance. In order to be effective, such third party organizations would themselves have to be subject to regulatory oversight, market forces, or both in providing their services. At the enforcement stage, local communities might be given the power to shut down a facility. Or consumers may choose to buy or not to buy certain products on the basis of their verified compliance with some established environmental standard. All of these examples illustrate the possible use of market forces to enhance the efficiency and effectiveness of regulation.

\footnotetext{
${ }^{3}$ Most countries follow a government-mandated eco-label system, e.g. Spindler (1995). The United States is an exception, and two private organizations currently compete for recognition in the eco-label market, namely, Green Seal and Scientific Certification Systems (see Orts, 1995: 1247-50 \& nn. 88, 91).

${ }^{4}$ See (Smith, 1993). The CERES Principles were given a significant boost in publicity when two Fortune 500 companies, Sun Co. and General Motors, signed negotiated versions (see Banks, 1994; Hemming, 1994).
} 
In understanding the motives that might move a business to comply or not comply with a set environmental standard, we note two types of rewards which businesses seek. The first relates to what we call the firm's "economic franchise", namely, the continued profitability to allow the firm to prosper or at least to remain viable. If a firm fails to satisfy its economic raison d'être, it loses its economic franchise and falls into bankruptcy or dissolution. The second reward, which in many respects interwines with the first, relates to what we call the "social franchise". ${ }^{5}$ Businesses pursue their economic objectives within constraints imposed by society. Primary among the social constraints on business are those imposed by law. Violation of legal standards risks significant economic costs in terms of civil and punitive fines. In addition, violation of law, particularly criminal law, risks very serious personal and moral costs. Beyond the confines of law are independent considerations of business ethics. A business firm, composed of people, not just balance sheets, must legitimate itself as a legal and moral entity if it is to continue to enjoy its social franchise without undue interference from its employees, customers, and neighbors.

In terms of these two kinds of rewards, conventional regulation focuses on affecting the economic calculations of businesses. It aims at influencing the calculations of the economic franchise by imposing civil fines to counterbalance any economic gain achieved by cutting corners on legal standards. Only through the heavy-handed method of criminal prosecution does this method of regulation significantly challenge a firm's claim to its social franchise, although very heavy civil penalties may have a similar effect. Where appropriate, criminal penalties impose severe moral and personal costs on violators, in addition to economic costs of criminal fines.

In contrast, IR opens up possibilities of influencing the economic and social franchises more broadly and more subtly. Dissemination of information about environmental performance can influence public opinion, which can effect a business' social, as well as economic franchise in concrete markets. In an approach emphasizing IR, rewards and punishments for environmental performance are given to businesses not just by government, but also, by economic markets and the public opinion of society-at-large and of smaller communities related directly to the firm, such as boards of directors or key professional organizations of employees. ${ }^{6}$

This three-stage conception of (1) the development of performance or specification standards, (2) monitoring and verifying behavior in accordance with them, and (3) the punishment/reward system to encourage good behavior reveals considerable flexibility in choice of regulation. At each stage, the simple and direct model of regulator and regulated becomes more complex when IR and market-based approaches to regulation are used to replace or reinforce the traditional command and control approach. We now consider how a market-based implementation of a management systems standard, as embodied in ISO 14000 , might provide considerable leverage in efficiently accomplishing the objective of assuring compliance with regulatory or industry best-practice standards for environmental performance while simultaneously providing the benefits of IR to affected stakeholders.

${ }^{5}$ I owe this terminology to my colleague, Irv Rosenthal. A third "regulatory franchise" required for continued viability might also be coined.

${ }^{6}$ For a recent discussion of social legitimation of environmental policy, see Ladeur (1995). 


\section{The structure of ISO 14000}

ISO 14000 is actually a series of environmental management standards (EMS). These standards are voluntary and, taken together, they provide guidelines for the development and maintenance of an overall management system, designed to meet individual company needs, but comforming to general requirements for effective environmental management. The standards themselves are being written by an international group of cooperating industrial groups, government environmental and standards organizations, under the general guidance of the International Organization for Standardization (ISO), a private sector, international standards body based in Geneva. Founded in 1947, ISO promotes international harmonization and development of manufacturing, product and communications standards. The closest relative to the ISO 14000 standards is the ISO 9000 standards for quality. ISO 9000 was set up as a management system standard in the 1980 s and spread rapidly throughout the world, as organizations found that standardization of documentation, training and data structures for quality could promote significant improvements not only within the boundaries of a single organization but across national and international supply chains. ISO 14000 began development in 1991, after the successful deployment of ISO 9000 standards, and the aspirations underlying ISO 14000 were motivated by the experience with ISO 9000 . Indeed, many organizations recognize synergies between ISO 9000 and ISO 14000 and they hope to achieve superior environmental performance by extending their ISO 9000 experience and management systems to incorporate additional environmental features required by ISO $14000 .{ }^{7}$

As foreseen in ISO 14000, EMS are management system standards and not performance standards. EMS help an organization establish and meet its own environmental policies through documented accountability and responsibility structures, communication and training programs and management control and review functions. Companies may choose to be certified for either specific facilities or for the company or division as a whole. EMS themselves do not set specific requirements for environmental compliance, but the EMS do call for a commitment to compliance with environmental laws, prevention of pollution and continual improvement of environmental performance. As we will note below, EMS can include specific compliance statements and procedures, and these can be audited as part of the ISO 14000 EMS certification process. Thus, ISO 14000 could, but is not required to, provide additional assurance of compliance with those laws and regulations with which the EMS itself asserts compliance. The following standards are the initial standards foreseen in the ISO 14000 series. ${ }^{8}$

${ }^{7}$ BVQI, a leading company in registering organizations under the related BS-7750 and EMAS (Eco-Management Audit Scheme), asserts that "if a company has ISO 9001 in place, they already have about $70 \%$ of the implementation know-how of ISO 14001. Many companies will integrate the two standards to have a more complete management system that will cover more of their business activities". From the BVQI Internet web site (http://www.bvqi.com), August 23, 1996. In addition to ISO 9000 , some sectors might be attracted to merge other standards and processes under the ISO 14000 umbrella. For example, in an industry such as food processing, a reconciliation of quality, health and environmental systems under ISO $9000 / 14000$ could be attractive, especially for small business where regulatory duplication is particularly onerous.

${ }^{8}$ At this point ISO 14001, 14004 and the audit standards ISO 14010-12 have all completed the full approval process, with official dissemination expected by the year's end (see ISO, 1996a). Notwithstanding the draft status of some of the ISO 14000 standards, many countries have already begun the process of deploying certification and registration procedures and many companies have begun the process of preparing their EMS for certification (see ISO, 1996b). 
ISO 14001: Environmental Management Systems - Specification with guidance for use.

ISO 14004: Environmental Management Systems - General guidelines on principles, systems and supporting techniques.

ISO 14010-12: Principles, qualification criteria and procedures for internal and external auditing.

ISO 14014: Initial review guidelines to determine a corporation's baseline operating position, typically used prior to establishing an EMS.

ISO 14020-22: Describes labeling principles such as self-declarations of environmental benefits of products.

ISO 14031: Guidance for measuring environmental performance over time.

ISO 14040-43: Establishes a methodology for a product's life cycle, including an assessment impact and improvement analysis.

ISO 14050: Terms and Definitions.

A closely related set of requirements/standards is that promulgated by the European Union under the Eco-Management Audit Scheme (EMAS). Like ISO 14000, EMAS is a voluntary program promoting continual environmental improvements in the private sector. EMAS identifies for the public (and publishes every six months the names of) those companies that meet EMAS standards. Companies meeting these standards may place an EUapproved logo and statement in their publications and letterhead. EMAS became operational for participation in April 1995. Many observers and non-EU governmental organizations have urged that EMAS be reconciled with ISO 14000 to assure international harmonization and to reduce what otherwise are feared to be effective barriers to trade. ${ }^{9}$ As currently implemented, EMAS has additional and more stringent requirements than ISO 14000 , including the requirement that the certification statement itself as well as specific information verifying continual performance improvement be made public. Note that while the ISO 14000 standards require a commitment to continual improvement, at least in the company's environmental management systems, they do not require a verification of continual improvement in environmental performance. Current plans call for the EU to reconcile EMAS and ISO 14000 by accepting ISO guidelines with an explanatory document specifying the additional EMAS requirements. However, the details of whether and how EMAS and ISO certification will eventually be reconciled remain uncertain. What is clear is that significant costs, both in potential trade barriers as well as in internal organizational costs for multinational companies, could and likely will result if such a reconciliation does not occur. For the purposes of this paper, I will continue to focus only on ISO 14000, joining in the general expectation that growing international pressure will result in such a reconciliation.

One final point is essential to note. The auditing requirement for ISO 14000 can be executed by either the organization itself (an internal audit) or by a qualified third party. Requirements for auditors are spelled out in ISO 14010-12. What one can expect to occur is that third-party external auditors will become the vehicle of choice, both because of the added element of objectivity of third parties, but also because of economies of scale in performing

${ }^{9}$ See Vogel (1995) for a discussion of international trade implications of environmental standards and Platzer et al. (1995) for a specific discussion of the trade implications of ISO 14000 and EMAS. 
the audit function and related value-added services provided by third parties. ${ }^{10}$ It is sometimes noted that small and medium-size companies, in particular, will want to undertake internal auditing procedures, rather than hire external auditors. In my view, this is very unlikely to be the case. Either external auditors will add sufficient value to make their services worthwhile, or small companies will not find it useful to become ISO 14000 certified in the first place. If, as was the case in ISO 9000, smaller companies become certified in order to satisfy larger customers downstream in the supply chain, then such customers will almost certainly require an external audit to verify ISO 14000 certification. Where there are sectorspecific benefits (e.g., chemical distribution, dry cleaning, etc.), one would expect trade organizations to help standardize generic EMS to capture best practices and to assure synergies with the regulatory process. Such generic EMS would again logically be in the hands of external service organizations to deploy and to audit. For these reasons, in what follows, I am going to consider only the case of external third-party certification.

Concerning the structure of implementation, ISO 9000 provides a reasonable model of what to expect. Third-party organizations, including consulting and auditing service companies, will provide services to assist companies in preparing for certification as well as auditing and certification services. Business and trade organizations can be expected to play a major role in establishing generic EMS and in assisting certification organizations to understand value-adding services which may accompany ISO 14000 certification or auditing. Government agencies may have responsibilities for licensing qualified auditors and auditing organizations and for continuing to monitor compliance with applicable laws and regulations. If ISO 14000 is an efficient way of improving compliance and performance, then one would expect it to become a global standard, just as ISO 9000 has in the quality arena, and to drive the very vision and structure of what constitutes effective environmental management systems and practice. Whether this will happen clearly depends on the balance of costs and benefits of ISO 14000 .

\section{The potential benefits of ISO 14000}

The potential benefits from ISO 14000 stem in part from the commonality of practice which standards are intended to promote, together with improvements in both cost and performance. In this section, I provide the rationale underlying what may be viewed currently as "hypotheses" about benefits which may arise from ISO 14000. As noted in McKiel (1995), the original vision for ISO 14000 was to:

- Promote a common approach to environmental management, similar to quality management as embodied in ISO 9000 ;

- Enhance organizations' abilities to attain and measure improvements in environmental performance; and

- Facilitate trade and remove trade barriers.

${ }^{10}$ Such value-added activities could include consulting on technology, loss control, pollution prevention, quality improvement and energy conservation initiatives, training and many other services which would naturally come to light as part of the process of conducting the EMS audits in a number of companies. 
I wish to examine the potential benefits from ISO 14000 under these general headings, but with specific reference to the following issues:

- Improved Community-Business Interaction;

- More Efficient Regulation;

- More Efficient Business Performance;

- More Efficient Risk Management and Insurance.

\section{Improved community-business interaction}

There are two potential benefits for local communities which could arise from ISO 14000. First, ISO 14000 could itself promote better environmental performance for companies structuring their EMS according to these standards, and this will clearly benefit external stakeholders. Second, ISO 14000 could promote better communication with the local community and better information. Following the Coasean argument (see below), this may provide the basis for additional performance benefits.

Ronald Coase (1960) argued that one way of approaching externalities such as environmental damages is to clarify the property rights involved and then let the parties negotiate appropriate terms. For example, if a firm owns the right to emit a certain amount per year of a given pollutant, then surrounding communities who may suffer damages from the pollutant would bargain with the firm to emit less of the pollutant and they would pay the firm to reduce its pollution if their damages were higher than the cost of pollution reduction. In the famous information, the resulting bargaining outcome will be Pareto efficient. The problem with this line of reasoning as a guide to policy is that the assumptions necessary for efficiency are rarely satisfied (see, e.g., Gruenspecht and Lave (1989)). Identifying pollution sources and owners and then bargaining with them is fraught with transactions costs and informational asymmetries.

Because of these problems, few would argue for the widespread application of a pure Coasean approach. But one interpretation of the move toward standards with third party audits would be to reduce the transaction costs of understanding and identifying pollution sources, thus making it less expensive to bargain effectively with agents controlling these sources about appropriate levels of risk and environmental impacts. This interpretation is especially compelling when one considers impacts which are largely local and borne by an identified group of stakeholders, such as a community hosting an industrial facility.

The key question from an informational perspective is whether the information that the company is required to publish is relevant, i.e. whether it is sufficient to allow the community to evaluate the actual or expected damages caused by the company. This is claimed by many not to be the case with eco-labels and with worst case scenarios. ${ }^{11}$ It could also be a

11 Concerning Eco-labels, see Spindler (1995). Concerning worst case scenarios, the recent hearings on the proposed regulation under 112(r) of the Clean Air Act provide a case in point. A great deal of industry opposition to certain proposals concerning the communication of worst case scenarios was based on the belief that such scenarios would encourage communities to focus on very low probability events when the real benefits from risk reduction expenditures might well lie in other areas, such as decreasing the expected losses from an event (in contrast to worst case losses). 
problem under contemplated implementations of ISO 14000 since there is no requirement per se in the EMS standard for release of specific information to the community. Thus, the basic hypothesis here on potential benefits to local communities can be summarized as follows: 12

Companies subscribing to ISO 14000 will have better environmental performance than those that do not. Moreover, information generated by ISO 14000 will be informative to local communities and will promote lower transaction costs for the communities (or their surrogates) by understanding the environmental performance of companies who elect certification under ISO 14000.

\section{More efficient regulation}

The traditional economic view of regulation was not much concerned with inefficiencies and costs introduced by the regulatory process itself. Williamson $(1979,1984)$ rectified this oversight by arguing that, especially in noncompetitive settings, an analysis of the "governance structure" mediating transactions required attention to the cost of governance itself. The regulatory setting is rife with potential for transactions costs, and there is growing literature on regulatory transaction costs..$^{13}$ This framework is of special interest in the area of environmental regulation, although no direct application of Williamson's work appears as yet to have been undertaken. Indeed, much of the recent political debate on compliance costs and market-based approaches to environmental regulation is focused on the poor costeffectiveness of the current regulations caused by high regulatory transactions costs.

While there does not appear to be any research on the issue, a standard such as ISO 14000 with third party verification has the potential for reducing regulatory transactions costs in both monitoring and enforcement. On the monitoring side, the use of third parties, together with an informed public, has the potential to increase the efficiency and service quality of monitoring and inspection services as compared to the more bureaucratic procedures within the government. The availability on a broad scale of standardized data on company operations could also be of value in diagnosing common factors leading to accidents or incidents. ${ }^{14}$

A key question on the effectiveness of third-party monitoring is not simply the reduction in regulatory transactions costs but the extent of ancillary benefits from the third-party activity (e.g., economies of scope between discovery of problems and repair of problems, better measurement and quality systems resulting from third-party services, and other technical support and advice resulting from the third-party activity which might improve company operations beyond simple assurance of regulatory compliance).

12 The intent here is to advance a number of empirically testable hypotheses. The reader may wish to consider the extent to which measurable criteria and data would be available to test these hypotheses. One source of such data in the US, for a large segment of environmentally sensitive industry, will be the accident history data required to be filed by 1999 and thereafter as part of compliance requirements with $112(r)$ of the Clean Air Act Amendments.

${ }^{13}$ See, e.g., the review in Crew and Kleindorfer (1986, chapter 7) and the discussion of "Goal-setting" in section 3 of Gruenspecht and Lave (1989).

${ }^{14}$ Exactly this point on the diagnostic value of publicly available information is made in recent U.S. Environmental Protection Agency discussions of IR (EPA, 1994). 
Concerning enforcement, the central issue will be whether ISO 14000 EMS will be implemented as an umbrella for a broad set of specific regulations. If the EMS objectives and policies clearly state the company's plans for compliance with a set of regulations, then an audit of the EMS under ISO 14000 will yield valuable information to both the public and the regulators on the company's compliance with these regulations. By focusing enforcement activities more on companies without the audited ISO 14000 stamp of approval, regulators would be increasing the effectiveness of enforcement expenditures. These considerations lead to the following hypothesis:

ISO 14000 will attract companies with an above average level of compliance with existing regulations. These companies will then find it in their interest to include in their EMS objectives and policies statements specific to some applicable regulations, against which they intend to provide a reliable signal to regulators of their compliance through third-party audit. The result will be reduced transactions costs (for both companies and regulatory agencies) of regulatory monitoring and enforcement, and higher levels of compliance.

\section{More efficient business performance}

There are two drivers of potential improvement in business performance. The first is the potential of ISO 14000 to drive internal organizational improvements in environmental performance, both in terms of costs as well as environmental impacts, by the EMS which requires attention to at least the basics of prudent environmental management practice. The second is the possibility that standardization in ISO 14000 may drive interorganizational learning through benchmarking.

Benchmarking of best practices has been practiced intensively for the past decade (e.g., Camp (1989)). This process is one of discovering improved practices in one organization and transferring these to another organization. Benchmarking is recognized to yield improved results when its scope and terminology for performance measurement have been standardized. Since such standardization is clearly the primary focus of ISO 14000, one might expect that its introduction will yield not just more uniform practices, but also better practices. Such practices would likely be transferred from one company to the next by third parties engaging in value-added services together with auditing and certification. They might also be transferred through more uniform product stewardship practices along the supply chain. We might summarize the possibility of such organizational improvements as follows:

ISO 14000 will yield improved cost and value performance for certified companies. It will also yield opportunities for discovering and transferring best practices among certified companies, which will be evident through improved performance of the ISO 14000 group of companies as a whole relative to business average performance. It is expected that early adopters will reflect better environmental performance (e.g., in terms of TRI data, accident records, life-cycle efficiencies, etc.) than later adopters, and that the reputation effects associated with this will lead to almost universal adoption in industrial sectors with significant environmental impacts.

\section{More efficient risk management and insurance}

There are several reasons to believe that ISO 14000 could lead to better risk management and to consequent reductions in liabilities and premiums for business. First, if EMS under ISO 14000 actually lead to improved environmental performance, these results are 
obvious consequences of market dynamics. More subtly, the results may arise because increased uniformity of practice within specific sectors resulting from standardization may lead to increased predictability, lower variance in losses and greater capacity devoted to environmental lines of insurance. To the extent that ISO 14000 leads to a greater reliance on the market rather than on regulatory solutions, there may be additional benefits in increased insurability of environmental risks due to a lessening of regulatory uncertainty (e.g., Faure (1995)). Finally, if ISO 14000 promotes a stronger basis of trust between companies, local communities and environmentalists, then the motivation for legal remedies for perceived damages and the reduction of "dread risk" (Slovic (1987)) could be reduced with direct consequences for insurance premiums to cover such damages. All of these premises rest on the following hypothesis:

ISO 14000 will reduce environmental impacts of business activity and, through increased uniformity practice within specific business segments, will promote more predictable liabilities for certified companies, with consequent improvements in their insurance rates and their relations with insurance companies. Moreover, the move to the market which ISO 14000 represents will reduce regulatory uncertainties promoting increased insurability of environmental risks.

In November of 1995, Global Environmental Management Systems conducted a survey of top environmental executives of 18 leading US Corporations, international consulting firms and ISO 14000 registrars concerning perceived benefits of ISO 14000 (see Burdick (1996)). Some of the results are given in Table 1 below. In spite of the apparent lukewarm responses on the strengths of ISO 14000 , registrar organizations (those expected to certify companies) indicate a strong demand for certification requests wwhich, according to ISO 14001 has already begun to develop.

What is not apparent from Table 1 are the many reservations and areas of concern which respondents indicated. Concerning "Overall Efficiency", some respondents indicated skepticism on whether increases in labor costs required to implement and maintain EMS will yield corresponding savings worth the effort. In part this will depend on third parties finding value adding activities (e.g., energy or material savings opportunities) and synergies as part of the EMS audit process.

Concerning regulatory impacts of ISO 14000 , respondents gave a significant number of comments on the need to improve this area in order to increase acceptance of ISO 14000. Suggested improvements include (recall this is a US survey): "Need the US EPA to make more tangible incentives to business"; "Reduction of inspection, monitoring and reporting"; "Reduction of time required for attaining permits"; "Decrease in fines"; "Protection of audit results"; and "Federal requirements for ISO 14001 registration for government projects": Clearly, reduced regulatory transactions costs and other regulatory incentives are very much in the mind of senior environmental executives as they consider adopting ISO 14000. 
Table 1:

Responses on perceived strengths \& weaknesses of ISO 14000 (Adapted from Burdick, 1996)

\begin{tabular}{|c|c|c|}
\hline $\begin{array}{l}\text { Area of potential impact } \\
\text { ISO } 14000\end{array}$ & $\begin{array}{l}\% \text { of respondents indicating } \\
\text { this is a likely strength of } \\
\text { ISO } 14000\end{array}$ & $\begin{array}{c}\% \text { of respondents indicating } \\
\text { this is a likely weakness of } \\
\text { ISO } 14000\end{array}$ \\
\hline Environmental performance & 7 & 22 \\
\hline Reducing trade barriers & 31 & 0 \\
\hline Promoting public awareness & 0 & 19 \\
\hline $\begin{array}{l}\text { Promoting the quality of } \\
\text { Environmental management }\end{array}$ & 25 & 10 \\
\hline $\begin{array}{l}\text { Improved overall efficiency } \\
\text { though cost savings in } \\
\text { materials, energy, labor, etc. }\end{array}$ & 11 & 28 \\
\hline $\begin{array}{l}\text { Improved risk management } \\
\text { and insurance }\end{array}$ & 14 & 0 \\
\hline $\begin{array}{l}\text { Improved regulatory } \\
\text { compliance and performance }\end{array}$ & 10 & 9 \\
\hline $\begin{array}{l}\text { Motivating organizational } \\
\text { participants to improve } \\
\text { environmental performance }\end{array}$ & 2 & 13 \\
\hline
\end{tabular}

\section{Problems and limitations of ISO 14000}

Achieving the above benefits presupposes that a number of limitations of ISO 14000 are eliminated. Most importantly, from the perspective of our earlier discussion of company social and economic franchises, what needs to be assured in that ISO 14000 leads to net economic benefits for each of the primary stakeholders involved: business, regulators and external stakeholders including local communities. We explore problems for each of these groups separately.

\section{Business}

The principal concern of companies is that ISO 14000 does not just become a paper exercise, which, while voluntary, becomes de facto mandatory, but with no improvements in efficiency. If ISO 14000 is to work for business, it must produce real economic benefits in terms of reductions in resources required to achieve compliance with regulations, possibly through reductions in inspection and monitoring for ISO certified companies, but also through increased efficiency in environmental management or through the transfer of best practices across companies. If ISO 14000 is, as it should be, driven by the market, then one can naturally expect third parties to look assiduously for value-adding activities, beyond mere audits, to enhance their customer focus and perceived service quality. 
One way in which a number of companies, especially small and medium-size companies, may benefit from ISO 14000 is through codifying regulatory requirements for particular sectors into generic EMS which may then be implemented, with trade organization support, efficiently throughout an industrial sector. ${ }^{15}$ By including explicit policy statements in the company's EMS and auditing these by third parties, significant increases in effective monitoring and enforcement resources could result. If the audits were effective and recognized as such by both regulators and the public, reduced regulatory oversight would clearly be appropriate, with resulting reduced regulatory transaction costs. The result could, on balance, achieve net benefits for all. But it remains to be seen whether such a balance can be achieved, especially for small and medium-size companies which do not face the same incentives as large companies do for regulatory compliance.

\section{Regulators}

The problems for regulators are not less difficult. They have a legal mandate to assure compliance with applicable laws and regulations. They cannot simply relinquish monitoring and enforcement responsibilities to the market. Many regulators may not even wish to do so, however promising the prospects may be, since bringing in the market may be a threat to their jobs. For both skeptics and enthusiasts, there will have to be a slow and careful transition to any new equilibrium, a transition marked by careful studies of whether and how ISO 14000 and its auditing process can be used as a reliable signal of improvement and compliance. In larger nations, founded on federalist principles, this will involve additional difficult issues of state (or regional)-federal jurisdiction and enforcement responsibilities. Unless and until ISO 14000 enjoys a credible body of pilot studies (and possibly supporting research) to assure its reliability as a signal of environmental excellence, regulators will have to maintain current enforcement procedures and responsibilities. To add to the complexity of the transition, there may need to be dual systems in place, for companies which elect to continue under the pre ISO 14000 system and for those who elect to move to ISO certification. ${ }^{16}$

An additional problem for regulators in implementing ISO 14000 will be the monitoring of auditor qualification and licensing procedures as well as quality control of the audits performed by these auditors. If these procedures are too lax, a "lemons market" for auditors will result (Akerlof, 1970) and the credibility of the entire process will be impaired. If qualifications procedures are too stringent, regulators will expend excess resources on licensing and monitoring auditor performance and competition in the auditor or third-party service market will be impaired. The developing European experience with EMAS auditors will be instructive in this regard.

15 For a discussion of one possible application of this kind of implementation in the context of Risk Management Planning under the new 112(r) Rule of the Clean Air Amendments, see Rosenthal et al. (1995). By organizing around sectors, best practices will likely be more easily discovered and applied. The sectoral approach will be especially attractive to sectors that are well organized, have a common technological base, and that see international certification as competitively attractive.

16 For a discussion of the political economy of the ISO process and the balancing act required among regulators and other constituencies, see Audley (1996). In all of this, the fundamental purpose of informational regulation (IR) should be recognized and promoted. The purpose of IR is not simply to provide the same kind of monitoring as under traditional command and control regulation, but rather to promote a sense of (eco-) systemic connectivity between all stakeholders. 


\section{External stakeholders}

From an external stakeholders' perspective, the critical issue is that ISO 14000 can present credible evidence that it promotes continual improvement in environmental performance and at least the same level of information availability as other available methods for community and external stakeholder involvement. As pointed out by McCloskey (1996), environmentalists to date have not been deeply involved in the development of ISO 14000 . Rather it has been an industry and regularity initiative. Moreover, the continuing reluctance by the business community to commit to publishing detailed information on company environmental performance as part of ISO 14000 has not been reassuring. It seems clear that the major focus for public acceptance of ISO 14000 will be industry and regulator positions on information revelation. Recall that ISO 14000 does require the company to specify as part of its EMS what its communication procedures are with both internal and external stakeholders. But no specific (measurable performance) requirements are imposed. If companies do not themselves agree, as a matter of good practice, to publish their environmental results so as to allow external stakeholders to understand and verify that continual improvement in environmental performance is taking place, then public skepticism of business commitment to the environment will continue and ISO 14000 will likely fail to gain the trust of the public. Absent such trust, it will only take a few accidents or serious incidents involving companies which are ISO 14000 certified (and such accidents will inevitably occur over time) for the public and its surrogates to conclude that ISO 14000 is just another magic show, designed for the benefit of business and to the detriment of the environment and the broader public.

Given the above comments, visible, tangible, externally developed/validated and publicly shared performance measures are essential. In the short term, these measures should focus on meeting standards. However, ISO-certified companies must strive in the long run for "beyond compliance" in terms of "noticeably better" results. Here, noticeably better may be a matter of communication style or other qualitative features by companies and not simply statistical verifiability of performance improvements.

It should be noted that ISO 14000 presents important opportunities for external stakeholders to help their business partners without relinquishing their own independence. The ISO "compact" may involve statements from public interest groups and surrogates about firm responsibility and accountability, based on the EMS audit. As in eco-labelling, these statements can be useful for the firm or the sector in question for marketing, investor and employee relations, community outreach and more. Clearly this can only work if ISO develops in the direction of promoting explicit communication of audited, measurable improvements in environmental performance.

Finally, just as small companies with limited expertise and resources may have trouble implementing ISO 14000, public interest groups may also have limited time, expertise and resources to apply to the ISO process. At the least, therefore, government and business must begin an education process to assist these parties to play their role in the IR process underlying ISO. Simply making information available. It must be understandable and actionable at the grass roots level, and this will require communication and education initiatives for the public. 


\section{Concluding comments}

Achieving a balance between various stakeholders' requirements, as embodied in the social and economic franchises of companies to operate, will require a period of experimentation and careful analysis. That we are in a state of experimentation and transition is perhaps the most important message to convey with respect to ISO 14000 . The potential benefits for international trade, for risk management and insurance and for improving environmental performance of business in an efficient manner are significant. These are the result of using information-based regulation and the market to provide new services and to reinforce regulatory oversight and community involvement through third-party audits aligned with company EMS. The question before us is whether this particular approach, fine tuned through a period of good faith negotiations among all stakeholders, can assure a robust balance between competing interests. Experimentation with different implementation models and pilot studies will hopefully begin to provide some answers to this question.

\section{REFERENCES}

AKERLOF, G., 1970, "The Market for Lemons. Quality, Uncertainty and the Market Mechanism", Quarterly Journal of Economics, pp. 488-500.

ALLEN, S., "EPA Turns from Fines to Jail for Polluters", Boston Globe, Apr. 3, 1994, at. 1.

AUDLEY, J. J., 1996, "Privatizing Public Regulations: The International Organization for Standardization 14000 Environmental Management Service", Purdue University, Indiana.

BANKS, J. R., Summer 1994, "CERES and Sun: A Value-Added Relationship",On Principle, CERES: Boston.

BARAM, M. S., 1994, "Multinational Corporations, Private Codes, and Technology Transfer for Sustainable Development", Environmental Law Reporter, 24, pp. 33-65.

BURDICK, D., "Benchmarking Perceptions of ISO 14001", Mimeo, 1996.

CAMP, R., Benchmarking, The Free Press, New York, 1989.

COASE, R. H., 1960, "The Problem of Social Cost", Journal of Law and Economics, 3, pp. 1-44.

CREW, M. A. and KLEINDORFER, P. R., 1987, The Economics of Public Utility Regulation, MIT Press: Cambridge.

Environmental Protection Agency (EPA), August, 1994, "Using Information Strategically to Protect Human Health and the Environment". EPA 270-K-94-002. Environmental Information and Assessment Committee; National Advisory Council for Environmental Policy and Technology.

FAURE, M. G., 1995, "The Limits to Insurability from a Law and Economics Perspective", The Geneva Papers, 77, pp. 454-462.

GRUENSPECHT, H. K. and LAVE, L. B., 1989, "The Economics of Health, Safety and Environmental Regulation", Chapter 26 in Richard Schmalensee and Robert D. Willig (eds.), Handbook of Industrial Organization, Vol. II, North Holland: Amsterdam.

HEMMING, B., Summer 1994, "GM Faces Up to Its Challenges", On Principle, CERES: Boston.

International Organization for Standardization (ISO), 1996a, "The ISO 14000 Environment", March 1996, ISO, Geneva.

International Organization for Standardization (ISO), 1996b, "Survey of ISO 9000 in the USA", ISO 9000 News, Vol. 5, No. 4, July/August, 1996, pp. 6-9. 
KLEINDORFER, P. R. and ORTS, E. W., 1996, "Informational Regulation of Environmental Risks", Working Paper, Wharton Center for Risk Management and Decision Processes, University of Pennsylvania, August.

LADEUR, K.-H., 1995, Das Umweltrecht der Wissensgesellschaft, Duncker \& Humbolt: Berlin.

McCLOSKEY, M., 1996, “ISO 14000: An Environmentalist's Perspective”, Mimeo, April 26, 1996.

McKIEL, M. C., "ISO 14000: International Environmental Management Standards", EPA Standards Network Fact Sheet (EPA/742-F-95-006), May 1995.

ORTS, E. W., 1995, "Reflexive Environmental Law", 89 Northwestern University Law Review, pp. 1227-1340.

PLATZER, M., HEIER, S., NOVAK, C. and HUSSER, J., 1995, The Future of Transatlantic Trade Relations: A U.S. Business Perspective, U.S. Chamber of Commerce, Washington, DC.

ROSENTHAL, I., JWEEPING, Er. and KUNREUTHER, H., 1995, "The Use of Third Parties in Implementing EPA's Proposed Rule on Risk Management Programs for Chemical Accidental Risk Prevention", Working Paper, Wharton Center for Risk Management and Decision Processes, University of Pennsylvania.

SLOVIC, P., 1987, "Informing and Educating the Public about Risk", in P. R. Kleindorfer and H. C. Kunreuther (eds), Insuring and Managing Hazardous Risks, Springer Verlag: Berlin, Chapter 10, pp. 307-333.

SMITH, J. A., III, 1993, "The CERES Principles: A Voluntary Code for Corporate Environmental Responsibility", 18, Yale Journal of International Law, pp. 307-17.

SPINDLER, G., 1995, "Umweltschutz durch private Prüfungen von Unternehmensorganisationen: Die EG-Oeko-Audit-VO", Working Paper, Faculty of Law, University of Frankfurt.

VOGEL, D., 1995, Trading Up, Harvard University Press, Cambridge, MA.

WALD, M. L., "Corporate Green Warrior: Sun Oil Takes Environmental Pledge", N.Y. Times, Feb. 11, 1993 , at D5.

WILLIAMSON, O. E., 1979, "Transactions Cost Economics: the Governance of Contractual Relations". Journal of Law and Economics, 22, pp. 233-61.

WILLIAMSON, O. E., 1984, "The Economics of Governance: Framework and Implications", Journal of Institutional and Theoreticcal Economics, 140, pp. 195-223. 